\title{
ACCELERATOR-DRIVEN ASSEMBLY FOR PLUTONIUM TRANSFORMATION
}

(ADAPT)

\author{
Gregory J. Van Tuyle, Michael Todosow, James Powell, and Donald Schweitzer \\ Brookhaven National Laboratory \\ Department of Advanced Technology \\ Upton, New York 11973
}

(516) $282-7960$

\begin{abstract}
A particle accelerator-driven spallation target and corresponding blanket region are proposed for the ultimate disposition of weapons-grade plutonium being retired from excess nuclear weapons in the U.S. and Russia. The highly fissile plutonium is contained within .25 to $.5 \mathrm{~cm}$ diameter siliconcarbide coated graphite beads, which are cooled by helium, within the slightly subcritical blanket region. Major advantages include very high one-pass burnup (over $90 \%$ ), a high integrity waste form (the coated beads), and operation in a subcritical mode, thereby minimizing the vulnerability to the positive reactivity feedbacks often associated with plutonium fuel.
\end{abstract}

\section{INTRODUCTION}

Of the technology options currently under discussion for possible disposition of the highly fissile plutonium being retired from nuclear weapons, the large particle accelerator offers some potential advantages in comparison to better-known technologies such as use as fuel in nuclear reactors or vitrification and burial. For example, one can hope to fission all of the plutonium safely in one or two accelerator-driven devices without the creation of additional waste actinides, and to leave the fission products in a form suitable for safe disposal within a few years. Further, owing to the large amount of fission energy released by the plutonium, the device can be a net power generator, i.e., the power generation can greatly exceed that required to run the accelerator.

A suitable high-power particle accelerator (a Linac) has been designed for the Accelerator Production of Tritium (APT), and can be assumed applicable (with only minor modifications) to the plutonium disposition mission (Todosow, et al., 1993). Similarly, work done on the APT target technologies has been significant, and provides a basis for initial target work for the plutonium mission (Van Tuyte, et al., 1993). BNL is proposing to use the APT Spallation Induced Lithium Conversion (SUC) Target neutron source design, with a plutonium-graphite fuel form in the subcritical blanket region based on several years of work on the Particle Bed Reactor (PBR). The components of the technology proposed by BNL are largely in hand, although the proposed integration of the technologies is new and unique. We propose to name the target technology "ADAPT", for Accelerator-Driven Assembly for Plutonium Transformation.

\section{THE ADAPT TARGET TECHNOLOGY}

The ADAPT target technology is based on a neutron spallation target (the source), which converts each high-energy proton $(\sim 1-3 \mathrm{GeV})$ into approximately 20 (lower energy) neutrons, and a blanket 
containing plutonium in a subcritical configuration. The reference source is based on the APT SILC Target source region, and is composed of an array of aluminum pressure tubes containing aluminumclad lead pins (1-cm diameter) cooled by heavy water. Alternative source concepts are also possible, e.g., tungsten cooled by helium gas, which would allow much higher temperatures than those allowable in the SIIC source. The challenge for this alternative source is to overcome the large neutron-capture cross section of tungsten by using a high-leakage geometry and a hard neutronic spectrum.

The ADAPT blanket region is based on a fuel form that offers two major desirable attributes in the proposed applications: it can be run to very high burnups (approaching 100\%), and is in a form where direct disposal (after cool-down) is a genuine option. In the original application in the PBR, small fuel particles (0.5-mm diameter) produced high power densities and operated at very high temperatures (Ludewig, et al., 1994). In the proposed plutonium disposition application, the operating environment is far less challenging, and larger fuel beads $(0.5-\mathrm{cm}$ diameter) are proposed. The beads are contained between two porous "frits" within fuel elements, with the helium coolant passing downward through the outer annular region in the element, radially inward through the frits and beds of fuel beads, and then upward through the coolant duct in the center of the fuel element. The subcritical blanket is composed of about 50 such fuel elements, and contains about $300 \mathrm{~kg}$ of plutonium. It is expected that in a single full power ( 3000 to $3600 \mathrm{MWt}$ ) unit about $25 \mathrm{~kg}$ of plutonium would be fissioned each week.

With the low inventory and high burnup, the first significant challenge is to develop a practical reloading scheme. Here, the use of fiuel beads is a major advantage in that one could reload or shuffle the beads weekly, possibly during periods when the accelerator would be down for maintenance. However, the working goal is to extend the period between reload/shuffling to between 3 and 6 weeks, if possible. Large reactivity swings due to Pu burmup are expected, so a scheme for using fuel shuffling, variable plutonium loading, burnable poisons, control rods, and/or variable accelerator current to compensate must be worked out. It is important to realize, however, that this will be an optimization effort, because the options are clearly available - one simply has to find the most practical means of compensating for the reactivity swings.

\section{SAFETY CONSIDERATIONS}

Another key area is safety, and the proposed machine would have some attractive safety characteristics, including subcritical operation (compensates for some difficult plutonium reactivity characteristics) and small inventories of plutonium and fission products. However, the blanket is essentially a high-power-density subcritical reactor, and in many respects the safety requirements will be those needed for large nuclear reactors. In the case of emergency coolant systems and containment requirements, the similarities will be strong. In the reactivity control areas, however, there will be major differences. In particular, by remaining subcritical, one gains the ability to shut down the machine quickly by tripping the proton beam. The key question will be how far one must stay subcritical, which will be driven by the maximum credible reactivity-insertion accident. While it is easy to develop this philosophy, it is far more difficult to assess various potential accidents at this time, so the maximum acceptable $\mathrm{K}_{\text {fff }}$ may remain uncertain until a conceptual design can be evaluated in more detail. This has the unfortunate impact of leaving the optimal accelerator current and energy 


\section{DISCLAIMER}

Portions of this document may be illegible in electronic image products. Images are produced from the best available original document. 
undetermined, because the proton beam energy and the $\mathrm{K}_{\text {eff }}$ essentially determine the blanket power level, and the power level determines the plutonium fission rate.

\section{WASTE STREAM}

Given the "waste" disposal mission, an essential question is what is the anticipated waste stream from the ADAPT target. It is currently believed the waste form will be nearly ideal for long term storage in repositories (Lotts, et al., 1992), but a more careful evaluation is necessary.

Because of the low plutonium loading in the porous graphite matrix, it is expected that fission gasses accumulated through almost complete burnup of the Pu inventory could be accommodated within the silicon-carbine and perhaps pyrolytic carbon coated beads. While the anticipated gas pressures would be within the capability of the coatings if unirradiated, it remains to be demonstrated that fully irradiated coatings could accommodate the gas pressure at $100 \%$ burnup. If this can be demonstrated, the next step will be to show the irradiated beads perform as well in leach testing as prior testing would suggest. Once the high fission product retention has been confirmed, many spent beads would be imbedded in tar and placed in a storage canister for the ultimate emplacement in a waste repository.

\section{THE ERBIUM OUESTION}

The primary rationale for operating the ADAPT Target in subcritical mode, as an accelerator target rather than as a reactor, is concern over positive reactivity feedbacks in highly fissile plutonium. The tendency of phutonium to fission more effectively in a harder neutronic spectrum raises stability and control issues, and introduces the possibility of power excursions. Subcritical operation provides some extra margins and options for dealing with this potential threat, but at the cost of considerable additional complexity.

Erbium has been proposed/used as a burnable poison in some reactor designs, and has a potentially useful tendency to capture neutrons in the "resonance" energy range. This introduces the possibility of using Erbium to counter the plutonium preference for faster neutrons. That is, by using enough erbium and an appropriate neutronic spectrum, a design team may be able to obtain negative reactivity feedbacks. If this could be achieved throughout the burnup cycle, as the plutonium and erbium inventories change, the advantages of subcritical operation would be greatly diminished, if not eliminated entirely

The neutronic design analyses required to determine the viability of the erbium option are very extensive. At the very least, we expect to be able to reduce the reactivity feedback issue using erbium, which would allow operation closer to criticality.

\section{THE END-OF-LIFE ISSUE}

The other driver for subcritical operation is the need/desire to fission essentially all of the weapons plutonium. Obviously, at some point the remaining mass of plutonium would be less than that required for criticality, and one could then use an accelerator to push the subcritical pile to complete 
burnup. This has been proposed by GA for the HTGR plutonium disposition option (Baxter, A. M., et al., 1993).

Alternate options would include leaving the balance of plutonium at moderately high burnup levels, or using a mix of uranium isotopes include U-233 and/or U-235 to supplement the remaining weapons plutonium.

\section{SUMMARY}

BNL is currently evaluating an accelerator driven subcritical target, designated ABC/ADAPT, as an ultimate disposition technology for weapons plutonium. The target is based on a fuels technology that was developed for the particle bed reactor, and that fuel provides excellent characteristics regarding high burnup and a high integrity waste form.

\section{Acknowledgments}

This work was performed under the auspices of the U.S. Department of Energy.

\section{References}

Todosow, M. , et al., (1993) "Nuclear Characteristics of an Accelerator-Driven Target-Blanket System", Trans ANS, 69, 424, November 1993.

Van Tuyle, G. J., et al., (1993) "Topical Report on a Preconceptual Design for the Spallation-Induced Lithium Conversion (SIC) Target for the Accelerator Production of Tritium", Brookhaven National Laboratory Report, BNL-52401, September 30, 1993.

Ludewig, H., et al., (1994) "Design of Particle Bed Reactors for the Space Nuclear Thermal Propulsion Program", Brookhaven National Laboratory Report, BNL-60306, May 1994.

Lotts, A L., et al., (1992) "Options for Treating High-Temperature Gas-Cooled Reactor Fuel for Repository Disposal", Oak Ridge National Laboratory Report, ORNL/TM-12027, UC-522, UC810, UC-811, February 1992.

Baxter, A. M., et al, (1993) "Combining an Accelerator and a Gas Turbine Modular Helium Reactor for Near Total Destruction of Weapons Grade Plutonium", Presented at the ADTT Conference, Las Vegas, NV, July 1994.

\section{DISCLAIMER}

This report was prepared as an account of work sponsored by an agency of the United States Government. Neither the United States Government nor any agency thereof, nor any of their employees, makes any warranty, express or implied, or assumes any legal liability or responsibility for the accuracy, completeness, or usefulness of any information, apparatus, product, or process disclosed, or represents that its use would not infringe privately owned rights. Reference herein to any specific commercial product, process, or service by trade name, trademark, manufacturer, or otherwise does not necessarily constitute or imply its endorsement, recommendation, or favoring by the United States Government or any agency thereof. The views and opinions of authors expressed herein do not necessarily state or reflect those of the United States Government or any agency thereof. 


\section{ADAPT Target to Dispose of Excess Plutonium}

\section{ADAPT: Accelerator-Driven Assembly for Plutonium Transformation}

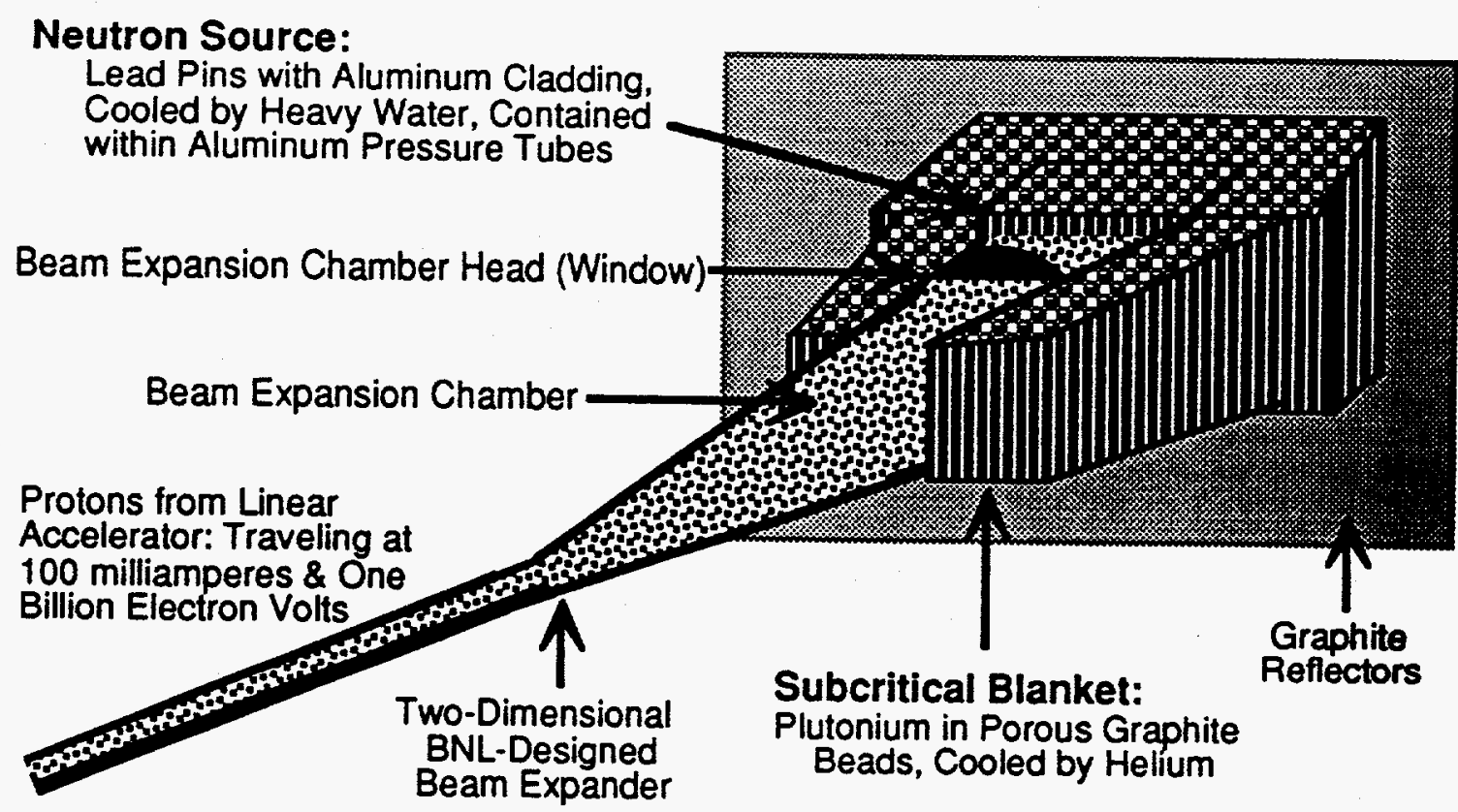

ADAPT Target - Top View

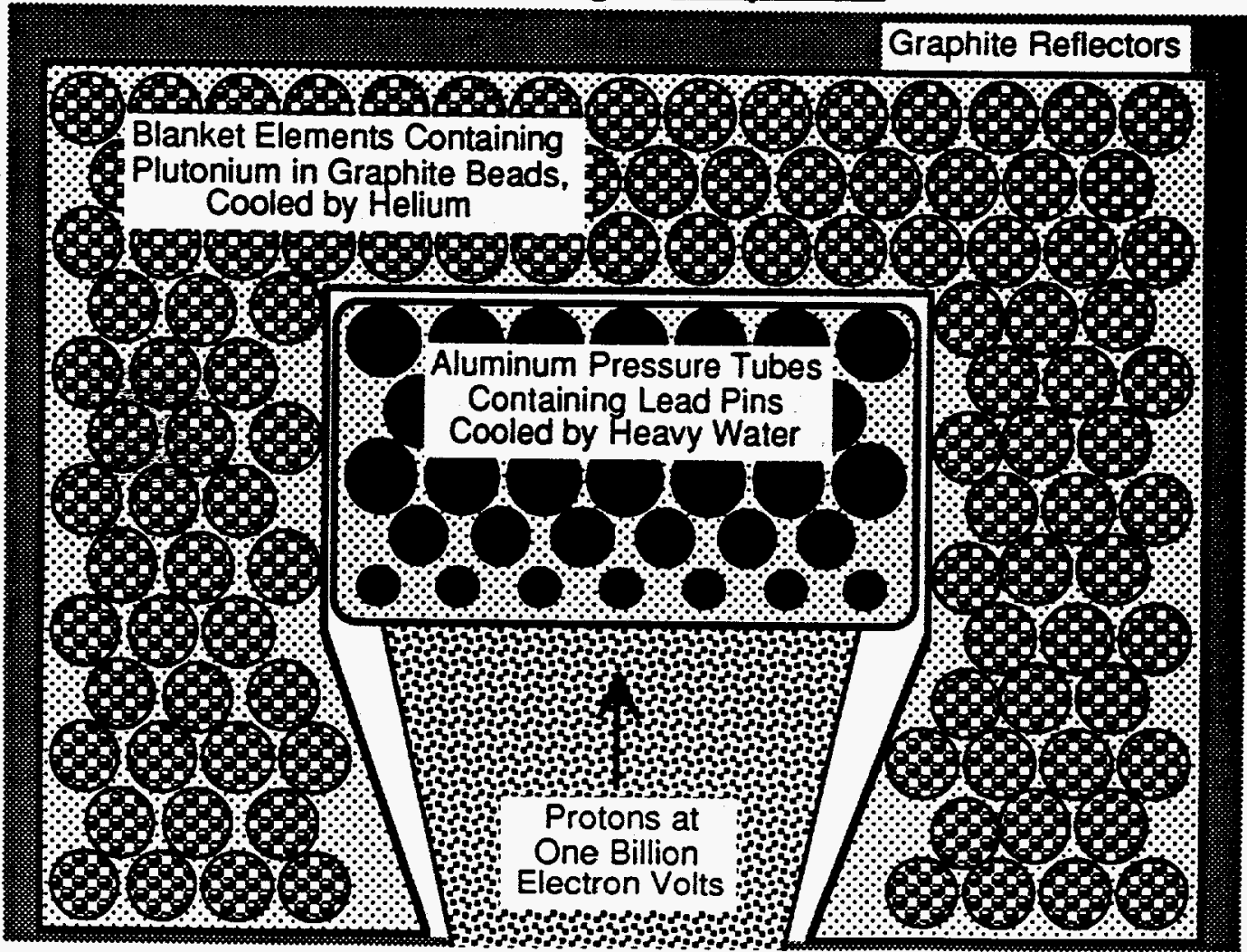

